\title{
Repeatability of the Evaluation of Perception of Dyspnea in Normal Subjects Assessed Through Inspiratory Resistive Loads
}

\author{
Andréia K. Fernandes ${ }^{*}, 1$, Bruna Ziegler², Glauco L. Konzen ${ }^{2}$, Paulo R.S. Sanches ${ }^{3}$, \\ André F. Müller ${ }^{3}$, Rosemary P. Pereira ${ }^{4}$ and Paulo de Tarso R. Dalcin ${ }^{4}$
}

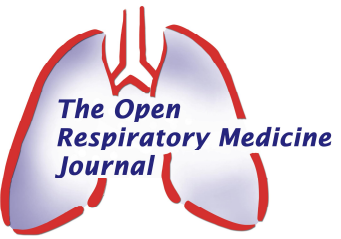

'Programa de Pós-Graduação em Ciências Pneumológicas, Universidade Federal do Rio Grande do Sul (UFRGS), Brazil

${ }^{2}$ Programa de Pós-Graduação em Ciências Pneumológicas, UFRGS, Brazil

${ }^{3}$ Serviço de Engenharia Biomédica do Hospital de Clínicas de Porto Alegre (HCPA), Brazil

${ }^{4}$ Faculdade de Medicina, UFRGS; Serviço de Pneumologia, HCPA, Brazil

\begin{abstract}
Purpose: Study the repeatability of the evaluation of the perception of dyspnea using an inspiratory resistive loading system in healthy subjects.

Methods: We designed a cross sectional study conducted in individuals aged 18 years and older. Perception of dyspnea was assessed using an inspiratory resistive load system. Dyspnea was assessed during ventilation at rest and at increasing resistive loads $\left(0.6,6.7,15,25,46.7,67,78\right.$ and returning to $\left.0.6 \mathrm{~cm} \mathrm{H}_{2} \mathrm{O} / \mathrm{L} / \mathrm{s}\right)$. After breathing in at each level of resistive load for two minutes, the subject rated the dyspnea using the Borg scale. Subjects were tested twice (intervals from 2 to 7 days).

Results: Testing included 16 Caucasian individuals ( 8 male and 8 female, mean age: 36 years). The median scores for dyspnea rating in the first test were 0 at resting ventilation and $0,2,3,4,5,7,7$ and 1 point, respectively, with increasing loads. The median scores in the second test were 0 at resting and $0,0,2,2,3,4,4$ and 0.5 points, respectively. The intraclass correlation coefficient was $0.57,0.80,0.74,0.80,0.83,0.86,0.91$, and 0.92 for each resistive load, respectively. In a generalized linear model analysis, there was a statistically significant difference between the levels of resistive loads $(p<0.001)$ and between tests $(p=0.003)$. Dyspnea scores were significantly lower in the second test.

Conclusion: The agreement between the two tests of the perception of dyspnea was only moderate and dyspnea scores were lower in the second test. These findings suggest a learning effect or an effect that could be at least partly attributed to desensitization of dyspnea sensation in the brain.
\end{abstract}

Keywords: Dyspnea, inspiratory resistive loading system, normal subjects, perception, repeatability.

\section{INTRODUCTION}

Dyspnea is a subjective experience of breathing discomfort that consists of qualitatively distinct sensations that vary in intensity [1-3]. The perception of dyspnea does not correlate with clinical severity or with the underlying pathology and may be affected by emotional, behavioral and cultural influences and environmental factors [4]. The investigation of the perceived level of dyspnea experienced by patients aims to make it possible to detect those individuals with abnormal sensitivity to breathlessness [5]. Asthma patients with low perception of dyspnea have higher morbidity and mortality due to delay in seeking medical care [5-7]. Identifying these patients would help to establish early treatment, improving survival and reducing health costs [8].

*Address correspondence to this author at the Travessa Miranda e Castro, 70/402, Bairro Santana, Porto Alegre, RS, CEP: 90040-280, Brazil;

Tel: +55 51 3508-6333; E-mail: andreiakist@hotmail.com
Several studies have used a system based on inspiratory resistive loads to evaluate the perception of dyspnea and to investigate factors associated with increased or decreased sensitivity to breathlessness [5, 7, 9-11]. This system for evaluating the perception of dyspnea consists of a circuit with inspiratory resistive loads of increasing magnitudes that induces the sensation of dyspnea by increasing the effort and work of breathing, while the individual expresses the degree of shortness of breath using a scale, such as the Borg scale $[12,13]$. The breathing pattern during the test can influence the magnitude of the perception of dyspnea [14], just as the increase of the inspiratory resistive loads can influence the breathing pattern. The dyspnea induced by the devices used in the laboratory can differ between individuals, even in healthy subjects $[9,15]$. Furthermore, hypoxia can suppress the sensation of dyspnea in asthmatics [10].

Repeatability and reproducibility of a method are essential factors to ensure reliable results for diagnostic use in clinical practice. Repeatability (r) refers to the strength of 
agreement between repeated measurements obtained under similar operating circumstances, with the same operator, and with the same equipment. It can be expressed by the following equation: $r=1.96 \sqrt{2} \alpha 1$, where $\sigma 1$ corresponds to the standard deviation. Reproducibility $(\mathrm{R})$ is the strength of agreement between repeated measurements obtained with the application of the same method under different operating conditions, by different operators, or with different equipment. It can be expressed by the following equation: $\mathrm{R}$ $=1.96 \sqrt{2} \sqrt{\alpha 1^{2}+\alpha 2^{2}}$, where $\sigma 2$ represents the standard deviation related to all other causes of variability of results not related to the repeatability $[10,16]$.

Although there are several reports investigating factors related to the variability of the perception of dyspnea assessed by inspiratory resistive load system, there is insufficient and conflicting evidence regarding the repeatability of the method $[17,18]$.

The objective of this study was to investigate the repeatability of the method to evaluate the perception of dyspnea in normal subjects during ventilation in an inspiratory resistive load system.

\section{METHODS}

\section{Study Design}

We conducted a cross-sectional study with data collected prospectively to evaluate the repeatability of the perception of dyspnea in healthy subjects. The volunteers underwent two tests with an interval of time from 2 to 7 days between tests.

The study was approved by the Hospital de Clínicas de Porto Alegre (HCPA) ethics committee and was registered with the number 08-064. All individuals studied had previously signed the Informed Consent Form.

\section{Population}

The study was conducted in the Service of Pneumology, HCPA, Porto Alegre, Brazil and included healthy subjects $\geq 18$ years of age. The volunteers were recruited with notices posted in the hospital and electronic announcements. The females that were of childbearing potential were allowed to be enrolled in the study as long as they were practicing a highly effective method of contraception (oral, injectable or implanted hormonal methods of contraception, placement of an intrauterine device or intrauterine system condom or occlusive cap with spermicidal foam $/ \mathrm{gel} / \mathrm{film} / \mathrm{cream} /$ suppository, male sterilization, or true abstinence). Acute respiratory tract complaints in the last 30 days, current or past smoking, abnormal spirometry or any chronic medical conditions such as asthma, chronic pain, cardiac or orthopedic disease were exclusion criteria. In addition, volunteers were excluded if they had traumatic injury.

\section{Study Procedures}

All subjects included in the study were submitted to a routine clinical evaluation conducted by the medical members of the research team. A standardized form was used for evaluating and recording the data. Pulmonary function tests were measured with a Pony graphic 4.0 spirometer (Cosmed Srl, Pavona di Albano, Roma, Italy). The forced vital capacity (FVC), forced expiratory volume in one second $\left(\mathrm{FEV}_{1}\right)$ and $\mathrm{FEV}_{1} / \mathrm{FVC}$ were measured three times, and the best trial was recorded. All results were expressed in liters and as percent predicted for age, height and sex $[19,20]$.

The perception of dyspnea was evaluated through an inspiratory resistive loads system, using a model previously reported in the literature [5] comprised of a two-way nonrebreathing valve (Hans-Rudolph, Kansas, USA). A plastic circular mouthpiece, with eight different orifices generated the inspiratory loads of increasing magnitude $(6.7,15.0$, 25.0, 46.7, 67.0 and $78.0 \mathrm{~cm} \mathrm{H}_{2} \mathrm{O} / \mathrm{L}$ per second, calculated according to a constant flow of $300 \mathrm{~mL} / \mathrm{s}$ ) (Fig. 1). The intrinsic resistance of the system was $0.6 \mathrm{~cm} \mathrm{H}_{2} \mathrm{O} / \mathrm{L}$ per second. Before the test, participants were familiarized with the apparatus and measurement procedures. After standardized instructions, volunteers were seated in a comfortable chair. Wearing a nose clip, volunteers breathed through a mouthpiece in the resistive loads system. The sensation of dyspnea was assessed during ventilation with increasing inspiratory resistive loads. After breathing at rest and at each level of resistance for two minutes, the subjects were questioned about the feeling of shortness of breath (dyspnea) experienced during the test using the modified Borg scale [13], ranging from 0 (no dyspnea) to 10 (maximal dyspnea). The heart rate and the peripheral oxygen saturation $\left(\mathrm{SpO}_{2}\right)$ were measured by pulse oximetry (NPB-40; Nellcor Puritan Bennett; Pleasanton; USA) during the test. To monitor the effects of dyspnea stimulation, inspiratory pressure, inspiratory time and respiratory frequency were measured continuously at the mouthpiece using computer software. Expiratory load was not applied. Subjects were free to choose their breathing rate, volume and flow to have as natural a breathing pattern as possible. Volunteers repeated the test with the same operator, same equipment and same method in a time interval from 2 to 7 days between tests.

\section{Statistical Analysis}

Data analysis was carried out with the Statistical Package for the Social Sciences (SPSS) version 18.0 (Chicago, Illinois) and Medcalc program, version 10.2.0 (MedCalc Software, Mariakerke, Belgium). Data were expressed as number and proportion of cases, mean \pm standard deviation (SD) or median (interquartile range).

Measurement variation was quantified as the withinsubject coefficient of variation, the intraclass correlation coefficient for average measures, or the weighted kappa coefficient of agreement (linear set of weight), as appropriate. The root mean square method was used to calculate the coefficient of variation, as proposed by Bland. The coefficient of variation was found separately for each subject, then squared, the mean determined, and the square root of that mean was taken. Confidence intervals were calculated for coefficient of variation and intra-class correlation coefficient. 


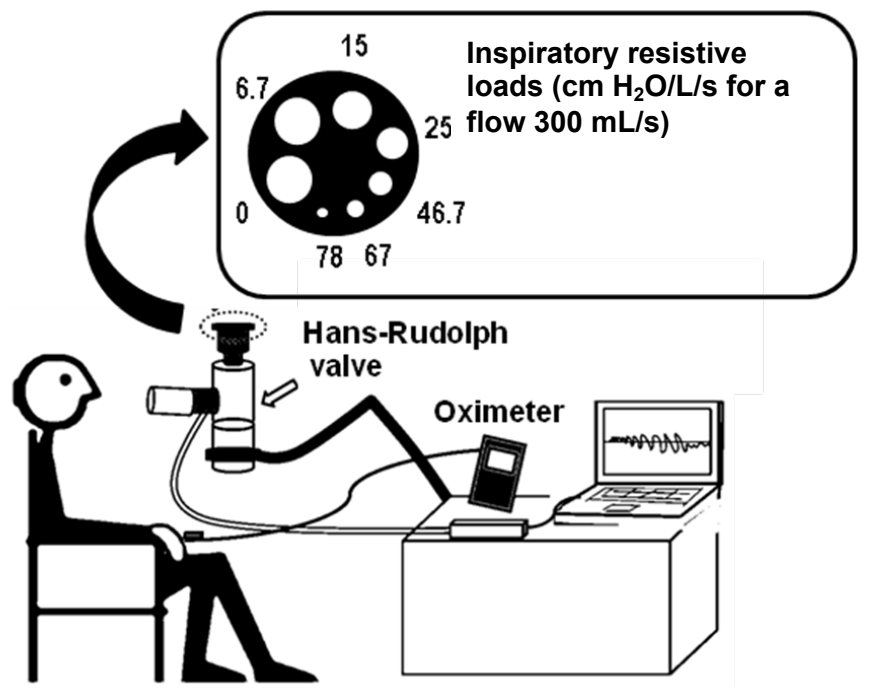

Fig. (1). Inspiratory resistive load system.

Generalized linear models were used to compare the dyspnea scores, inspiratory pressures and respiratory frequencies between the two tests during the inspiratory resistive loads. Correlations were determined using Spearman's rank correlation coefficient. Kaplan-Meier curves, stratified by test, were compared with the log rank test, to compare the completion of the perception of dyspnea test during inspiratory resistive loads.

The statistical significance level was set at $\mathrm{p}<0.05$. All probabilities reported were two-tailed.

\section{RESULTS}

The study included 16 Caucasian individuals, 8 men and 8 women. The mean age was $36.3 \pm 11.9$ years $(19-61$ years) and the mean body mass index (BMI) was $23.9 \pm 2.8 \mathrm{~kg} / \mathrm{m}^{2}$ (18.7 to $\left.28.7 \mathrm{~kg} / \mathrm{m}^{2}\right)$. Nine subjects practiced physical activity $\geq 2$ times/week. Most individuals had completed higher educational level. The mean $\mathrm{FEV}_{1}$ was $98.75 \pm 9.75 \%$ of predicted and the mean FVC was $95.31 \pm 10.12 \%$ of predicted (Table 1).

Table 2 presents the variation in the measurement of dyspnea scores between the two resistive loads tests. The median scores in the first test were $0,2,3,4,5,7,7$ and 1 for the steps of application of inspiratory loads of $\cong 0 ; 6.7 ; 15.0$; $25.0 ; 46.7 ; 67.0,78.0$ and $\cong 0 \mathrm{~cm} \mathrm{H}_{2} \mathrm{O} / \mathrm{L}$ per second, respectively. The median scores in the second test were 0,0 , $2,2,3,4,4$ and 0.5 points, respectively. The kappa coefficient of agreement was $0.78,0.46,0.58,0.33,0.57$, $0.56,0.73$ and 0.52 for each point, respectively. The intraclass correlation coefficient was $0.88,0.69,0.90,0.63,0.93$, $0.80,0.95$ and 0.74 for each load, respectively.

Table 1. Demographic characteristics and pulmonary function of subjects.

\begin{tabular}{|c|c|}
\hline Characteristics & \\
\hline Subjects, $\mathrm{n}$ & 16 \\
\hline Age (years), mean $\pm \mathrm{SD}$ & $36.3 \pm 11.9$ \\
\hline Sex (male/female), $n$ & $8 / 8$ \\
\hline Body mass index $\left(\mathrm{kg} / \mathrm{m}^{2}\right)$, mean $\pm \mathrm{SD}$ & $23.9 \pm 2.8$ \\
\hline Race (Caucasian), n & 16 \\
\hline \multicolumn{2}{|l|}{ Educational level, n (\%) } \\
\hline$\leq 8$ years of school & $2(12.5 \%)$ \\
\hline$>9$ years school and $<$ high school & $2(12.5 \%)$ \\
\hline$\geq$ high school & $12(75.1)$ \\
\hline Physical activity $\geq 2 \mathrm{x} /$ week & $9(56.3 \%)$ \\
\hline $\mathrm{FEV}_{1}(\mathrm{~L})$, mean $\pm \mathrm{SD}$ & $3.5 \pm 0.7$ \\
\hline $\mathrm{FEV}_{1}(\% \text { predict })^{*}$, mean $\pm \mathrm{SD}$ & $98.8 \pm 9.8$ \\
\hline $\mathrm{FVC}(\mathrm{L})$, mean $\pm \mathrm{SD}$ & $3.8 \pm 0.7$ \\
\hline $\mathrm{FVC}(\% \text { predict })^{*}$, mean $\pm \mathrm{SD}$ & $95.3 \pm 10.1$ \\
\hline
\end{tabular}

$\mathrm{n}=$ number of cases; $\mathrm{SD}=$ Standard deviation; PEFR = peak expiratory flow rate; $\mathrm{FEV}_{1}=$ forced expiratory volume in one second, $\mathrm{FVC}=$ forced vital capacity. *Percent predicted for age, height and sex (Pereira, et al.: J Bras Pneumol 2007 Aug; 33(4): 397- 406).

Fig. (2) shows generalized linear models for Borg dyspnea scores during increasing steps of resistive loads between the two tests. There was a statistically significant difference between the steps of resistive loads $(\mathrm{p}<0.001)$ and between the tests $(p=0.003)$. Values of dyspnea scores were significantly lower in the second test.

Table 2. Measurement variation of dyspnea scores between the two resistive loads tests.

\begin{tabular}{|c|c|c|c|c|c|c|c|c|c|}
\hline \multirow{2}{*}{ Loads $\left(\mathrm{cm} \mathrm{H} \mathrm{H}_{2} \mathrm{O} / \mathrm{L} / \mathrm{S}\right)$} & \multicolumn{2}{|c|}{$1^{\circ}$ Test } & \multicolumn{2}{|c|}{$2^{\circ}$ Test } & \multirow{2}{*}{ SE } & \multirow{2}{*}{ Kw } & \multirow{2}{*}{ Kw 95\%CI } & \multirow{2}{*}{ ICC } & \multirow{2}{*}{ ICC $95 \% \mathrm{CI}$} \\
\hline & Mean \pm SD & Median (IR) & Mean \pm SD & Median (IR) & & & & & \\
\hline$\cong 0$ & $0.9 \pm 1.3$ & $0(2.0)$ & $1 \pm 1$ & $0(2.0)$ & 0.080 & 0.78 & $0.62-0.94$ & 0.88 & $0.70-0.96$ \\
\hline 6.7 & $1.9 \pm 1.7$ & $2(2.5)$ & $2 \pm 2$ & $0(3.0)$ & 0.117 & 0.46 & $0.23-0.69$ & 0.69 & $0.31-0.88$ \\
\hline 15 & $2.9 \pm 2.5$ & $3(3.3)$ & $2 \pm 3$ & $2(3.0)$ & 0.105 & 0.58 & $0.38-0.79$ & 0.90 & $0.73-0.96$ \\
\hline 25 & $4 \pm 3.0$ & $4(3.0)$ & $2 \pm 2$ & $2(3.0)$ & 0.112 & 0.33 & $0.11-0.55$ & 0.63 & $0.19-0.87$ \\
\hline 46.7 & $4 \pm 2.0$ & $5(5.0)$ & $3 \pm 2$ & $3(4.0)$ & 0.089 & 0.57 & $0.39-0.74$ & 0.93 & $0.79-0.98$ \\
\hline 67 & $5 \pm 3.0$ & $7(5.0)$ & $4 \pm 3$ & $4(5.0)$ & 0.096 & 0.56 & $0.37-0.74$ & 0.80 & $0.48-0.93$ \\
\hline 78 & $5 \pm 3.0$ & $7(5.0)$ & $4 \pm 3$ & $4(5.0)$ & 0.078 & 0.73 & $0.58-0.89$ & 0.95 & $0.83-0.98$ \\
\hline$\cong 0$ & $2 \pm 2.0$ & $1(1.0)$ & $1.1 \pm 1.6$ & $0.5(2.0)$ & 0.162 & 0.52 & $0.20-0.84$ & 0.74 & $0.34-0.91$ \\
\hline
\end{tabular}

$\mathrm{SD}=$ standard deviation; $\mathrm{IR}=$ interquartile range; $\mathrm{SE}=$ standard error; $\mathrm{CI}=95 \%$ confidence interval; $\mathrm{Kw}=$ weighted Kappa coefficient of agreement; ICC $=$ intraclass correlation coefficient for average measures. 


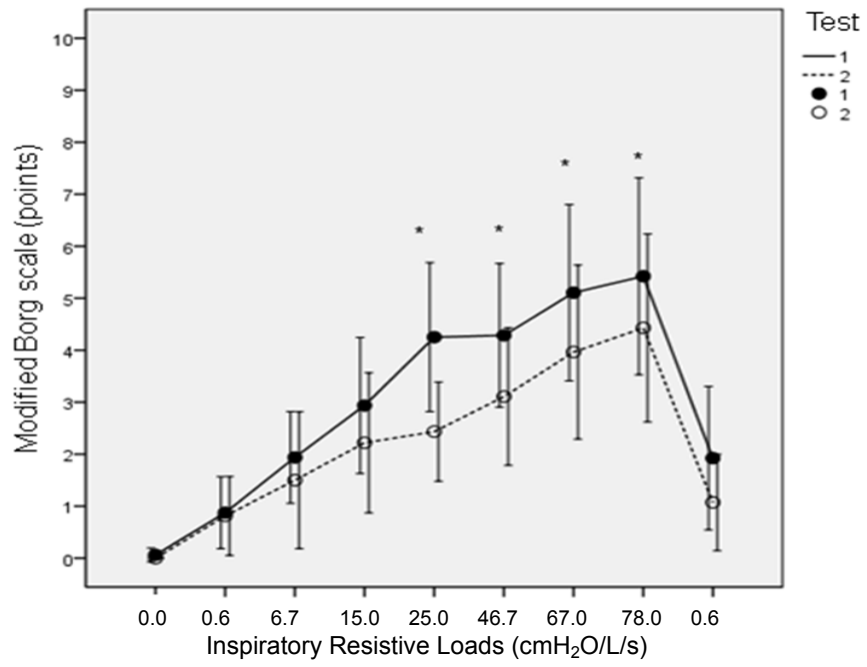

Fig. (2). Generalized Linear Model Between Two Tests for Perception of Dyspnea Scores. There was a significant difference between the steps of resistive loads $(p<0.001)$ and between the tests $(\mathrm{p}=0.003)$.

In the first test, the mean inspiratory pressures generated in each step of inspiratory loads were $3.2,5.4,8.8,12.5$,
$14.4,15.7,14.6$ and $4.4 \mathrm{cmH}_{2} \mathrm{O}$, respectively. In the second test, the mean inspiratory pressures were $3.9,5.4,7.6,10.2$, $12.3,14.7,16.3$ and $4.7 \mathrm{cmH} 2 \mathrm{O}$, respectively. The intraclass correlation coefficients were $0.57,0.80,0.74,0.80$, $0.83,0.86,0.91$ and 0.92 for each step, respectively (Table $3)$. In the analysis by the generalized linear model, as the magnitude of the loads increased, mean inspiratory pressure increased significantly $(\mathrm{p}<0.001)$, but without a difference between groups $(\mathrm{p}=0.59)$.

In the first test, the mean respiratory frequencies (breaths over $2 \mathrm{~min}$ ) observed in each step of inspiratory loads were $25.1,23.3,24.7,24.1,20.7,22.4,21.2$ and 21.5 , respectively. In the second test, the mean respiratory frequencies were: $29.1,25.8,24.1,20.9,19.8,18.3,20.1$ and 20.9 breaths over 2 minutes. The intra-class correlation coefficients were for each step: $0.74,0.94,0.92,0.60,0.57,0.62,0.70$ and 0.95 (Table 3). In the analysis by generalized linear model, as the magnitude of the loads increased, mean respiratory frequencies decreased significantly $(p<0.001)$, but without significant difference between the tests $(p=0.81)$.

As the magnitude of the loads increased, there were no significant differences for $\mathrm{SpO} 2$ and heart between loads and between tests.

Table 3. Measurement variation of inspiratory pressures and of respiratory frequency between the two resistive loads tests.

a. Inspiratory Pressures.

\begin{tabular}{|c|c|c|c|c|c|c|}
\hline Loads $\left(\mathrm{cm} \mathrm{H} \mathrm{H}_{2} \mathrm{O} / \mathrm{L} / \mathrm{S}\right)$ & $1^{\circ}$ Test & $2^{\circ}$ Test & CV (\%) & CV 95\%CI (\%) & ICC & ICC $95 \%$ CI \\
\hline 6.7 & $5.4 \pm 3.4$ & $5.4 \pm 2.8$ & 28.5 & $16.6-36.8$ & 0.80 & $0.525-0.927$ \\
\hline 15 & $8.8 \pm 5.6$ & $7.6 \pm 4.3$ & 28.8 & $20.1-35.5$ & 0.74 & $0.407-0.902$ \\
\hline 46.7 & $14.4 \pm 10.9$ & $12.3 \pm 7.9$ & 21.8 & $12.9-27.9$ & 0.83 & $0.541-0.940$ \\
\hline 67 & $15.7 \pm 12.3$ & $14.7 \pm 0.6$ & 22.7 & $11.9-29.8$ & 0.86 & $0.609-0.951$ \\
\hline 78 & $14.6 \pm 9.9$ & $16.3 \pm 2.2$ & 21.9 & $15.5-26.7$ & 0.91 & $0.735-0.972$ \\
\hline$\cong 0$ & $4.4 \pm 2.8$ & $4.7 \pm 2.8$ & 20.2 & $9.6-26.9$ & 0.92 & $0.751-0.974$ \\
\hline
\end{tabular}

b. Respiratory Frequency (Breaths Over 2 min).

\begin{tabular}{|c|c|c|c|c|c|c|}
\hline \multirow{2}{*}{ Loads $\left(\mathrm{cm} \mathrm{H} \mathrm{H}_{2} \mathrm{O} / \mathrm{L} / \mathrm{S}\right)$} & $1^{\circ}$ Test & $2^{\circ}$ Test & \multirow{2}{*}{ CV $(\%)$} & \multirow{2}{*}{ CV 95\% CI (\%) } & \multirow{2}{*}{ ICC } & \multirow{2}{*}{ ICC $95 \% \mathrm{CI}$} \\
\hline & Mean \pm SD & Mean \pm SD & & & & \\
\hline$\cong 0$ & $25.1 \pm 11.9$ & $29.1 \pm 20.4$ & 19.9 & $12.8-25.1$ & 0.74 & $0.399-0.900$ \\
\hline 6.7 & $23.3 \pm 17.8$ & $25.8 \pm 17.1$ & 22.2 & $10.0-29.7$ & 0.94 & $0.844-0.980$ \\
\hline 15 & $24.7 \pm 18.7$ & $24.1 \pm 14.0$ & 14.9 & $8.2-19.4$ & 0.92 & $0.791-0.972$ \\
\hline 25 & $24.1 \pm 18.7$ & $20.9 \pm 7.8$ & 22.6 & $6.8-31.3$ & 0.60 & $0.149-0.846$ \\
\hline 46.7 & $20.7 \pm 8.7$ & $19.8 \pm 8.7$ & 31.8 & $8.2-44.2$ & 0.57 & $0.075-0.837$ \\
\hline 67 & $22.4 \pm 13.9$ & $18.3 \pm 6.7$ & 22.9 & $10.6-30.7$ & 0.62 & $0.155-0.860$ \\
\hline 78 & $21.2 \pm 10.2$ & $20.1 \pm 7.9$ & 18.3 & $11.0-141.5$ & 0.70 & $0.272-0.899$ \\
\hline$\cong 0$ & $21.5 \pm 10.3$ & $20.9 \pm 9.7$ & 12.5 & $7.7-140.7$ & 0.95 & $0.855-0.986$ \\
\hline
\end{tabular}

$\mathrm{SD}=$ standard deviation; $\mathrm{CV}=$ coefficient of variation; $\mathrm{CI}=95 \%$ confidence interval; $\mathrm{ICC}=$ intraclass correlation coefficient for average measures 
Fig. (3) presents correlations between Borg dyspnea scores and inspiratory pressures during each inspiratory resistive load for both tests. Borg dyspnea scores were significantly correlated with inspiratory pressure $(r=0.49$ and $p<0.001$, for the first test; $r=0.36$ and $p<0.001$, for the second test).

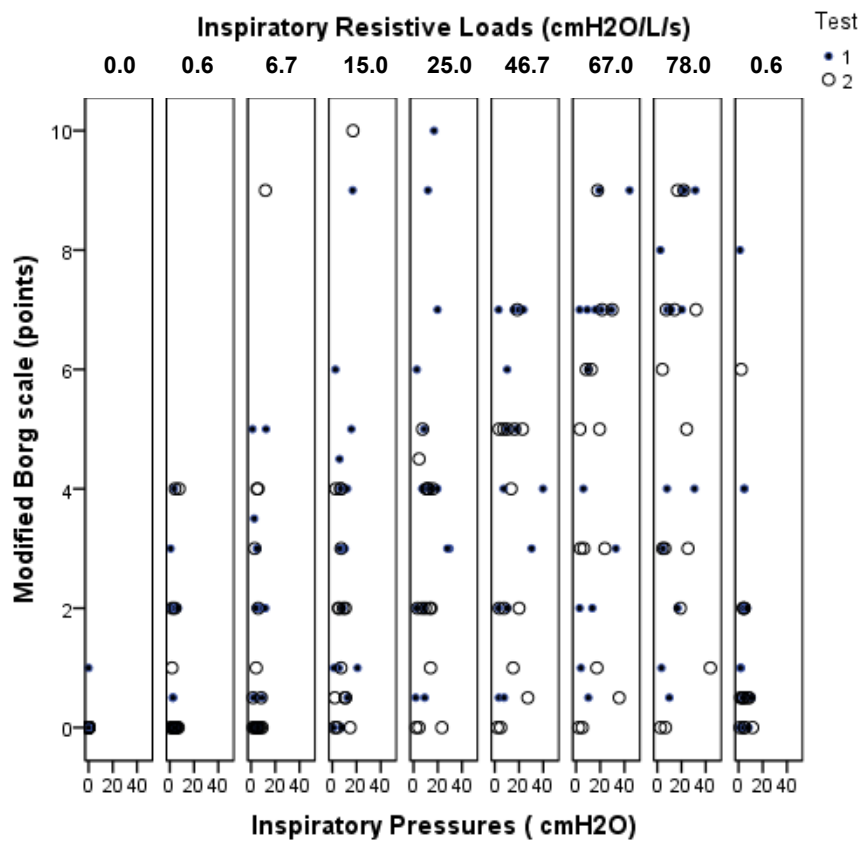

Fig. (3). Correlations Between Borg Dyspnea Scores and Inspiratory Pressures for Both Resistive Loads Tests $(r=0.49$ and $p$ $<0.001$, for the first test; $r=0.36$ and $p<0.001$ ).

Fig. (4) presents the Kaplan-Meier analysis of proportion of subjects that completed resistive loads testing. Thirteen $(81.3 \%)$ subjects performed the whole evaluation in the first test compared to $14(87.5 \%)$ in the second test (log rank test $=0.647$ ). Three individuals drop out of the study in the first test (subject number 5 at inspiratory load of $67 \mathrm{~cm}$ $\mathrm{H} 2 \mathrm{O} / \mathrm{L}$ per second, reporting Borg score of 9; subject number 7 at inspiratory load of $25 \mathrm{~cm} \mathrm{H} 2 \mathrm{O} / \mathrm{L}$ per second, reporting Borg score of 9 ; subject number 14 at inspiratory load of $25 \mathrm{~cm} \mathrm{H} 2 \mathrm{O} / \mathrm{L}$ per second, reporting Borg score of 10). Two individuals dropped out of the study in the second test (subject number 7 at inspiratory load of $25 \mathrm{~cm} \mathrm{H} 2 \mathrm{O} / \mathrm{L}$ per second, reporting Borg score of 4; and subject number 14 at inspiratory load of $15 \mathrm{~cm} \mathrm{H2O/L}$ per second, reporting Borg score of 10. The main reasons for dropping out of the study were dyspnea and exhaustion.

\section{DISCUSSION}

This study evaluated the repeatability of the evaluation of the perception of dyspnea induced by inspiratory resistive loads in healthy subjects. Repeatability and reproducibility are different measurement conditions which will give rise to different estimates of precision. Repeatability conditions are when replicate measurements are made in one laboratory, by a single analyst, using the same equipment over a short time period. A common definition of reproducibility conditions is when the replicate measurements are made by different analysts, working in different laboratories, using different equipment over an extended time period.

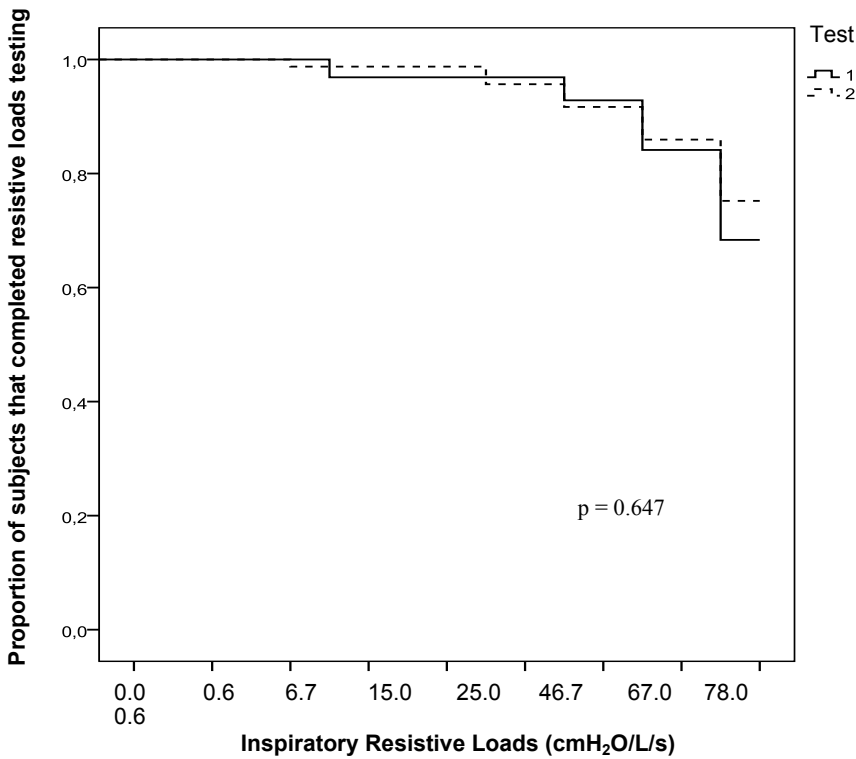

Fig. (4). Kaplan-Meier Analysis of Proportion of Subjects that Completed Resistive Loads Testing (log rank test=0.647).

There was moderate agreement in dyspnea scores for each level of resistive loads. Dyspnea scores were significantly lower in the second test. However, the inspiratory pressure generated against various resistive loads and respiratory frequencies did not differ significantly between the tests. These findings could suggest a learning effect through the ventilation system of resistive loads associated with a better control of the sensation of dyspnea by cortical afferents or because the individual became more familiar with the procedure and thereby more comfortable while doing the second test. Otherwise, this finding could be at least partly attributed to desensitization of dyspnea sensation in the brain. Desensitization to dyspnea is often discussed as a mechanism to explain benefit in the rehabilitation of COPD patients. A common hypothesis used to explain the mechanism is alleviation of fear by repetitive performance of exercise tasks in a safe and supervised environment [21-24].

Several studies have shown that dyspnea is multidimensional and that there may be differences between sensory and emotional aspects of its perception $[9,25]$. The level of the perception of dyspnea assessed by induction systems of dyspnea differs between people; however, there are few studies assessing the repeatability of these tests $[17$, $18]$.

Some studies suggest that dyspnea may be evaluated through the creation of multidimensional scales to assess qualitative aspects of sensory and emotional symptoms [11]. In our study, the method used to measure the perception of dyspnea was the modified Borg scale [13]. The modified Borg scale comprises a simple and validated instrument that has been widely used in clinical practice to evaluate dyspnea $[12,26]$.

The respiratory rate decreased significantly during breathing through inspiratory resistive loads of increasing magnitude in both tests in relation to the resting situation, which is a typical finding in studies that use resistive loads system, producing increasing respiratory effort $[9,11,27$, 
28]. Previous studies demonstrated that changes in ventilatory parameters during exercise are associated with the level of dyspnea $[29,30]$.

In our study, the perception of dyspnea increased progressively according to the increase of the inspiratory pressure generated at each step of resistive loads, as demonstrated in previous works [11, 14]. However, the novel finding in this study was the recognition that the correlation between dyspnea scores and inspiratory pressures was higher in the first test $(r=0.490)$ compared to the second one $(\mathrm{r}=0.363)$, which can be attributed to a learning effect and a reduced perception of this symptom.

In the present study, after breathing at each level of resistive load for two minutes without resting, volunteers were asked to rate their feeling of dyspnea. The fact that the test was performed without pausing may explain why the test was discontinued in three patients in the first occasion and in two patients in the second occasion. However, there was no difference in interruptions between the two tests.

Dyspnea perception has been already analyzed mainly during exercise. Stark et al. [31] induced breathlessness by submaximal graded exercise in healthy subjects while objective measurements of cardiorespiratory function were made. Breathlessness was assessed with serial visual analogue scales, but with various measures to enhance repeatability. A high level of reproducibility was obtained in spite of the subjective nature of the assessment. Mador et al. [32] evaluated the 5 weeks reproducibility of Borg scale ratings of the effort to breathe (Borg) and the degree of discomfort evoked by breathing in patients with COPD during exercise. They conclude that during incremental exercise Borg ratings of dyspnea are not as reproducible as physiologic indices in patients with COPD. Grant et al. [33] compared the reproducibility and the sensitivity to change of visual analogue scales, Borg scales, and Likert scales in normal subjects during submaximal exercise. This study suggested that subjective scales can reproducibly measure symptoms during steady-state exercise and can detect the effect of a drug intervention. Also, Chetta et al. [34] studied in asthmatics the score of bronchoconstriction-associated breathlessness at $20 \%$ fall in FEV1 evaluated on a Borg scale. They showed a good reproducibility and consider that this allows the serial evaluation of patient's breathlessness perception by this technique in clinical settings and in the physiology laboratory.

The clinical implication of the study is related to the repeated use of the test to assess the same subject over time. In this circumstance, the possibility of the individual becoming acclimated should be considered and may in itself justify a change in the perception of dyspnea. Additional studies are needed to quantify the magnitude and extent of this variation along a greater number of repeated measurements.

The current study has several limitations. The first limitation was the small number of subjects studied. Although the difference between the two tests was statistically significant, the small sample size may have contributed to the large confidence interval for the variation. The second limitation was the fact that only the repeatability (keeping the same conditions, the same operator and a short interval between tests) was studied. The variation of the test could be even higher under reproducibility conditions (different conditions, different operators and longer time interval between the tests). The third limitation was that the subjects studied were exclusively healthy volunteers and the results cannot be extrapolated to disease states. The fourth limitation was that we did not apply a randomized sequence of inspiratory resistive loads. Randomized presentations of different loads might be an alternative method that avoids the perception by patients of the progressive magnitude of the loads.

The agreement between the two tests of the perception of dyspnea induced by inspiratory resistive loads was only moderate and dyspnea scores were lower in the second test. These findings provide evidence for a learning effect or could be at least partly attributed to desensitization of dyspnea sensation in the brain during the repetitive performance of the test. The perception of dyspnea may be modified by previous experience. The subject may develop better control of the sense of cortical afference and/or learn to ventilate in the system with repeated measures. This effect should be considered when repeatedly performing the test over time.

\section{CONFLICT OF INTEREST}

The authors confirm that this article content has no conflict of interest.

\section{ACKNOWLEDGEMENTS}

We thank Vânia Naomi Hirakata, Statistics Department, Hospital de Clínicas de Porto Alegre, for their support in the statistical analyses.

\section{REFERENCES}

[1] Dyspnea. Mechanisms, assessment, and management: a consensus statement: American Thoracic Society. Am J Respir Crit Care Med 1999; 159(1): 321-40.

[2] Harver A, Mahler DA, Schwartzstein RM, Baird JC. Descriptors of breathlessness in healthy individuals: distinct and separable constructs. Chest 2000; 118(3): 679-90.

[3] Smith J, Albert P, Bertella E, Lester J, Jack S, Calverley P. Qualitative aspects of breathlessness in health and disease. Thorax 2009; 64(8): 713-8.

[4] Lansing RW, Gracely RH, Banzett RB. The multiple dimensions of dyspnea: review and hypotheses. Respir Physiol Neurobiol 2009; 167(1): 53-60.

[5] Kikuchi Y, Okabe S, Tamura G, et al. Chemosensitivity and perception of dyspnea in patients with a history of near-fatal asthma. N Engl J Med 1994; 330(19): 1329-34.

[6] Magadle R, Berar-Yanay N, Weiner P. The risk of hospitalization and near-fatal and fatal asthma in relation to the perception of dyspnea. Chest 2002; 121(2): 329-33.

[7] McFadden ER, Jr. Fatal and near-fatal asthma. N Engl J Med 1991; 324(6): 409-11.

[8] Castro M, Zimmermann NA, Crocker S, Bradley J, Leven C, Schechtman KB. Asthma intervention program prevents readmissions in high healthcare users. Am J Respir Crit Care Med 2003; 168(9): 1095-9.

[9] von LA, Dahme B. Differentiation between the sensory and affective dimension of dyspnea during resistive load breathing in normal subjects. Chest 2005; 128(5): 3345-9.

[10] Eckert DJ, Catcheside PG, Smith JH, Frith PA, McEvoy RD. Hypoxia suppresses symptom perception in asthma. Am J Respir Crit Care Med 2004; 169(11): 1224-30. 
[11] Banzett RB, Pedersen SH, Schwartzstein RM, Lansing RW. The affective dimension of laboratory dyspnea: air hunger is more unpleasant than work/effort. Am J Respir Crit Care Med 2008; 177(12): 1384-90.

[12] Cullen DL, Rodak B. Clinical utility of measures of breathlessness. Respir Care 2002; 47(9): 986-93.

[13] Borg GA. Psychophysical bases of perceived exertion. Med Sci Sports Exerc 1982; 14(5): 377-81

[14] Killian KJ, Bucens DD, Campbell EJ. Effect of breathing patterns on the perceived magnitude of added loads to breathing. J Appl Physiol Respir Environ Exerc Physiol 1982; 52(3): 578-84.

[15] Adams L, Chronos N, Lane R, Guz A. The measurement of breathlessness induced in normal subjects: individual differences. Clin Sci (Lond) 1986; 70(2): 131-40.

[16] British Standards Institution Part 1. Precision of test methods, part 1: guide for the determination of repeatability and reproducibility for a standard test method 1979

[17] Eastwood PR, Hillman DR, Finucane KE. Ventilatory responses to inspiratory threshold loading and role of muscle fatigue in task failure. J Appl Physiol 1985; 76(1): 185-95.

[18] Eastwood PR, Hillman DR, Morton AR, Finucane KE. The effects of learning on the ventilatory responses to inspiratory threshold loading. Am J Respir Crit Care Med 1998; 158(4): 1190-6.

[19] Sociedade Brasileira de Pneumologia e Tisiologia. Diretrizes para Testes de Função Pulmonar. J Brasil Pneumol 2002; 1-221.

[20] Pereira CA, Sato T, Rodrigues SC. New reference values for forced spirometry in white adults in Brazil. J Bras Pneumol 2007; 33(4): 397-406.

[21] Carrieri-Kohlman V, Douglas MK, Gormley JM, Stulbarg MS. Desensitization and guided mastery: treatment approaches for the management of dyspnea. Heart Lung 1993; 22(3): 226-34.

[22] Carter R, Coast JR, Idell S. Exercise training in patients with chronic obstructive pulmonary disease. Med Sci Sports Exerc 1992; 24(3): 281-91.

[23] Cooper CB. Desensitization to dyspnea in COPD with specificity for exercise training mode. Int J Chron Obstruct Pulmon Dis 2009; 4: $33-43$.
[24] Migliore A. Management of dyspnea guidelines for practice for adults with chronic obstructive pulmonary disease. Occup Ther Health Care 2004; 18(3): 1-20.

[25] von LA, Ambruzsova R, Nordmeyer S, Jeske N, Dahme B. Sensory and affective aspects of dyspnea contribute differentially to the Borg scale's measurement of dyspnea. Respiration 2006; 73(6): $762-8$.

[26] Wilson RC, Jones PW. Long-term reproducibility of Borg scale estimates of breathlessness during exercise. Clin Sci (Lond) 1991; 80(4): 309-12.

[27] Daubenspeck JA, Rhodes ES. Effect of perception of mechanical loading on human respiratory pattern regulation. J Appl Physiol (1985 ) 1995; 79(1): 83-93.

[28] Harver A, Mahler DA. Perception of increased resistence to breathing. In: Kotses H, Harver A, Eds. Self-management of asthma. New York: Decker 1998; pp. 35-61.

[29] Noseda A, Carpiaux JP, Schmerber J, Valente F, Yernault JC Dyspnoea and flow-volume curve during exercise in COPD patients. Eur Respir J 1994; 7(2): 279-85.

[30] el-Manshawi A, Killian KJ, Summers E, Jones NL. Breathlessness during exercise with and without resistive loading. J Appl Physiol 1986; 61(3): 896-905.

[31] Stark RD, Gambles SA, Lewis JA. Methods to assess breathlessness in healthy subjects: a critical evaluation and application to analyse the acute effects of diazepam and promethazine on breathlessness induced by exercise or by exposure to raised levels of carbon dioxide. Clin Sci 1981; 61(4): 429-39.

[32] Mador MJ, Rodis A, Magalang UJ. Reproducibility of Borg scale measurements of dyspnea during exercise in patients with COPD. Chest 1995; 107(6): 1590-7.

[33] Grant S, Aitchison T, Henderson E, et al. A comparison of the reproducibility and the sensitivity to change of visual analogue scales, Borg scales, and Likert scales in normal subjects during submaximal exercise. Chest 1999; 116(5): 1208-17.

[34] Chetta A, Castagnaro A, Foresi A, et al. Assessment of breathlessness perception by Borg scale in asthmatic patients: reproducibility and applicability to different stimuli. J Asthma 2003; 40(3): 323-9.

(C) Fernandes et al.; Licensee Bentham Open.

This is an open access article licensed under the terms of the Creative Commons Attribution Non-Commercial License (http://creativecommons.org/licenses/by-nc/3.0/) which permits unrestricted, non-commercial use, distribution and reproduction in any medium, provided the work is properly cited. 